\title{
SISTEM PAKAR DIAGNOSIS PENYAKIT HIPERTENSI DENGAN MENGUNAKAN METODE FORWARD CHAINING DAN TOERI PROBABILITAS
}

\author{
Emma Rosinta Simarmata \\ Program Studi Komputerisasi Akuntansi \\ Universitas Methodist Indonesia \\ emros2016@gmail.com
}

\begin{abstract}
At this time hypertension is a disease that endangers the community a lot because people often ignore it because this disease does not quickly affect the body but will slowly damage health. Hypertension is not contagious but can trigger other diseases, such as stroke and heart disease. The habit of people who will check their health after experiencing problems causes delays in their help. Symptoms of hypertension can be detected early so that people can prevent the seriousness of the disease. The expert system is one of the fields of science that can help the public to check whether a person has hypertension and the type of hypertension and the percentage of possible diseases he suffers because the expert system can be designed how to work like an expert. The expert system designed uses several stages, namely (1) system requirements analysis, (2) input and output design, (3) coding and (4) testing. This expert system will be represented in the form of rules, the method of reasoning using the forward chaining method and probability theory in calculating the percentage of rules that are fulfilled. The form of output (results) from the expert system is in the form of diagnostic results based on the symptoms given and suggestions that are in accordance with the diagnosis used are forward chaining, namely drawing conclusions from several types of hypertension obtained from symptoms. The output of the system is the type of hypertension diagnosed and the solution for the diagnosis. Keyword : Sistem Pakar, Forward Chaining, Hipertensi, Diagnosa
\end{abstract}

Keyword : Sistem Pakar, Forward Chaining, Hipertensi, Diagnosa

\section{PENDAHULUAN}

Penyakit Hipertensi (Tekanan Darah Tinggi) sering kali disebut the silent killer (pembunuh senyap) karena sebagian besar penderitanya tidak mengalami tandatanda atau gejala, sehingga tidak menyadari bahwa tubuhnya telah terkena hipertensi. Dalam beberapa kasus, penderita baru mengetahuinya setelah terjadi komplikasi.[1]. Penyakit ini tidak menular namun bisa terbentuk karena sifat genetik serta pola hidup yang tidak seimbang. Untuk mengetahui apakah seseorang sudah terkena penyakit hipertensi dapat diketahui dengan gejalagejala yang dirasakan didalam tubuh dan kehidupan seharihari.

Dengan mengetahui secara dini penyakit hipertensi ini maka semakin besar peluang kesembuhannya. Untuk mengetahui apakah seseorang sudah terkena hipertensi maka dibutuhkan suatu aplikasi yang dapat diakses setiap waktu tanpa harus menunggu waktu untuk konsultasi ke dokter namun aplikasi itu dapat bekerja layaknya seperti dokter (ahli) sehingga sistem pakar merupakan salah satu solusi yang dapat digunakan untuk pemecahan masalah diatas.

Dalam penelitian ini penulis membangun Aplikasi sistem pakar berbasis web dengan menggunakan metode Forward Chaining sebagai teknik untuk penelusuran dalam penarikan kesimpulan sesuai dengan fakta yang diberikan user dan menggunakan teknik probabilitas untuk menentukan nilai kepastian dari setiap aturan dikarenakan bebarapa gejala yang mungkin tidak terpenuhi oleh sistem. Teknik probabilitas ini diusulkan oleh Shortliffe dan Buchanan pada tahun 1975 yang bertujuan untuk mengakomodasi ketidakpastian pemikiran seorang pakar.

\section{KAJIAN TEORI}

Sistem pakar adalah suatu program komputer yang mengandung pengetahuan dari satu atau lebih pakar manusia mengenai suatu bidang spesifik. Jenis program ini pertama kali dikembangkan oleh periset kecerdasan buatan pada tahun 1960-an dan 1970-an dan diterapkan secara komersial selama 1980-an. Bentuk umum sistem pakar adalah suatu program yang dibuat berdasarkan suatu set aturan yang menganalisis informasi (biasanya diberikan oleh pengguna suatu sistem) mengenai suatu kelas masalah spesifik serta analisis matematis dari masalah tersebut. Tergantung dari desainnya, sistem pakar juga mampu merekomendasikan suatu rangkaian tindakan pengguna untuk dapat menerapkan koreksi. Sistem ini memanfaatkan kapabilitas penalaran untuk mencapai suatu simpulan.[3]

Metode Forward Chaining, Runut maju berarti menggunakan himpunan aturan kondisi-aksi. Dalam metode ini, data digunakan utnuk menentukan aturan mana yang akan dijalankan kemudian aturan tersebut dijalankan. Ilustrasi dari metode Forward Chaining dapat dilihat pada Gambar 1 dan Gambar 2

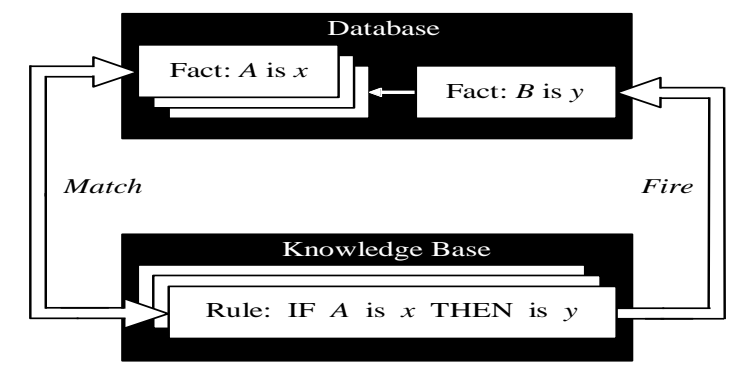

Gambar 1. Prosedur Siklus Mesin Inferensi Melalui Match-fire 


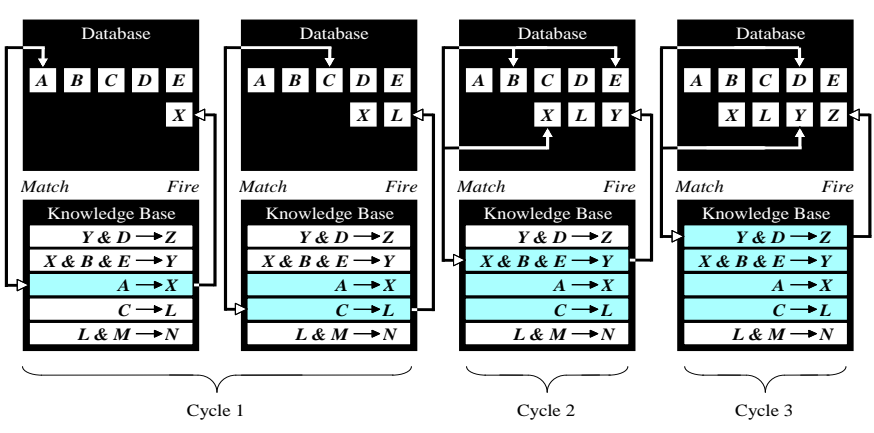

Gambar 2. Penelusuran Inference Chain dengan Metode Forward Chaining

\section{Hipertensi}

Hipertensi atau yang biasa disebut tekanan darah tinggi merupakan peningkatan tekanan darah sistolik di atas batas normal yaitu lebih dari $140 \mathrm{mmHg}$ dan tekanan darah diastolik lebih dari $90 \mathrm{mmHg}$ [2].

\section{Hipertensi Primer (Esensial)}

Hipertensi primer tidak bisa disembuhkan, akan tetapi bisa dikontrol dengan terapi yang tepat. Dalam hal ini, faktor genetik mungkin berperan penting untuk pengembangan hipertensi primer dan bentuk tekanan darah tinggi yang cenderung berkembang secara bertahun-tahun.[3] Hipertensi primer atau esensial umumnya terjadi karena faktor keturunan atau gaya hidup yang tidak sehat, seperti merokok, terlalu banyak mengonsumsi natrium (garam), stres, malas bergerak, mengonsumsi alkohol berlebihan, dan obesitas.

\section{Hipertensi Sekunder}

Penyebab hipertensi pada jenis ini, yaitu karena kondisi medis lain yang menyertainya. Beberapa kondisi medis yang bisa menyebabkan darah tinggi, yaitu sleep apnea, masalah pada ginjal, tumor pada kelenjar adrenal, masalah pada tiroid, atau diabetes.[4. Hipertensi sekunder memiliki ciri dengan peningkatan tekanan darah dan disertai penyebab yang spesifik, seperti penyempitan arteri renalis, kehamilan, medikasi tertentu, dan penyebab lainnya. Hipertensi sekunder juga bisa bersifat menjadi akut, yang menandakan bahwa adanya perubahan pada curah jantung[5]. Hipertensi sekunder jarang menimbulkan gejala. Gejala yang muncul umumnya berasal dari penyakit yang mendasari hipertensi sekunder dan bisa baru diketahui saat penderita melakukan pemeriksaan untuk penyakit tersebut.[6]

\section{Teori Probabilitas}

Definisi probabilitas,misalkan sebuah peristiwa E dapat terjadi sebanyak $\mathrm{n}$ kali di antara $\mathrm{N}$ peristiwa yang saling ekslusif (saling asing/terjadinya peristiwa yang satu mencegah terjadinya peristiwa yang lain) dan masingmasing terjadi dengan kesempatan yang sama. Maka probabilitas terjadinya peristiwa $\mathrm{E}$ adalah $\mathrm{P}(\mathrm{E})=\mathrm{n} / \mathrm{N}$, dengan batas-batas: $0<=\mathrm{P}(\mathrm{E})<=1 \ldots . .(1)$
Jika $\mathrm{P}(\mathrm{E})=0$, maka diartikan peristiwa $\mathrm{E}$ pasti tidak terjadi, sedangkan jika $\mathrm{P}(\mathrm{E})=1$, maka diartikan peristiwa peristiwa $\mathrm{E}$ pasti terjadi. Apabila $\bar{E}$ menyatakan bukan peristiwa $\mathrm{E}$, maka diperoleh $\mathrm{P}(\bar{E})=1-\mathrm{P}(\mathrm{E})$....(2) atau berlaku hubungan: $\mathrm{P}(\mathrm{E})+\mathrm{P}(\bar{E})=1$...

Probabilitas Bersyarat, Jika P(A) menyatakan probabilitas kejadian A, P(B) menyatakan probabilitas kejadian B dan probabilitas A dan B terjadi bersama-sama disimbolkan oleh $\mathrm{P}(\mathrm{A} \cap \mathrm{B})$ atau $\mathrm{P}(\mathrm{B} \cap \mathrm{A})$, Probabilitas bahwa kejadian A terjadi jika kejadian $B$ terjadi terlebih dahulu disebut probabilitas bersyarat $\mathrm{P}(\mathrm{A} \mid \mathrm{B})$, dan besarnya adalah: $\mathrm{P}(\mathrm{A} \mid \mathrm{B})=\frac{P(A \cap B)}{P(B)} \ldots . . . . .(4)$. Dengan cara yang sama, probabilitas bahwa kejadian B terjadi jika kejadian A terjadi lebih dahulu adalah : $\mathrm{P}(\mathrm{B} \mid \mathrm{A})=\frac{P(A \cap B)}{P(A)}$, karena $\mathrm{P}(\mathrm{B} \cap \mathrm{A})=\mathrm{P}(\mathrm{A} \cap \mathrm{B}), \quad$ maka diperoleh : $\mathrm{P}(\mathrm{A} \mid \mathrm{B})=$ $\frac{P(B \mid A) x P(A)}{P(B)}$

\section{METODE PENELITAIN}

Rancangan Data Flow Diagram terdiri dari 3 level sistem yaitu Data Flow Diagram level 0, level 1, level 3,dapat dilihat pada gambar di bawah ini :

\section{Data Flow Digram Level 0}
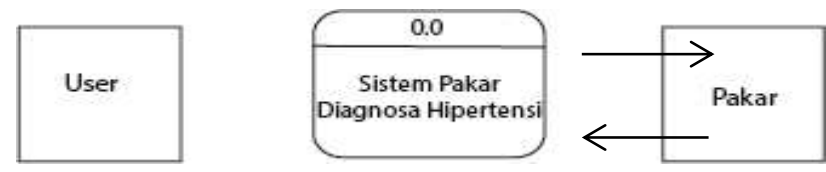

Gambar 3 Data Flow Diagram Level 0

Pada Gambar 3 menerangkan bahwa sistem berinteraksi dengan dua sumber data, yaitu pakar dan user. Tanda panah menunjukan masukan dan keluaran sistem. Seorang pakar memasukan basis pengetahuan ke dalam sistem yang berupa gejala ,basis aturan maupun saran untuk penyakit yang diderita oleh user, setelah diinput oleh pakar maka keluaran berupa hasil output yang di-input. Sedangkan user akan menjawab pertanyaan-pertanyaan yang diajukan oleh program, dan sistem akan memberikan hasil analisis(output) berdasarkan gejala yang diderita oleh user. Output yang dihasilkan atau hasil analisis dari sistem tersebut berupa jenis penyakit yang diderita, seberapa persen keyakinan dari penyakit yang dialami, dan solusi simple oleh pakar untuk penyakit yang diderita.

\section{Data Flow Diagram Level 1}

Data Flow Diagram Level 1 merupakan turunan dari Data Flow Diagram Level 0 yang mengambarkan aliran data dan detail proses-proses yang akan diuraikan lebih rinci dari Level 0 . 


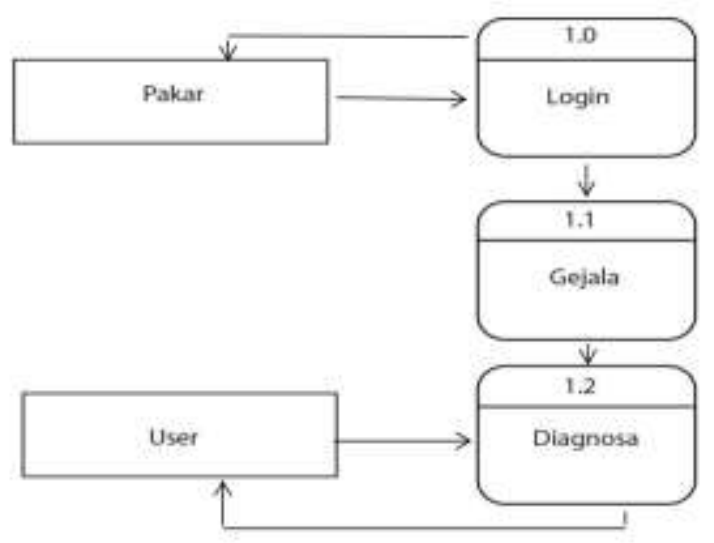

Gambar 4 Data Flow Diagram Level 1

Pada Gambar 4, seorang pakar masuk ke dalam sistem pakar melalui login, bagi pakar akan mengisikan email dan password, untuk mengakses form pakar, dan jika pakar belum terdaftar maka pakar bisa mengregistrasi untuk pakar baru. Dari login, seseorang pakar dapat menginput (memasukan) gejala dan basis aturan, dan pakar juga bisa mengedit maupun menghapus gejala, penyakit, dan basis aturan agar program lebih update (memperbaharui sistem yang ada). Dari data yang diinput maka program akan memasukan ataupun mengupdate data yang diinput ke dalam database untuk keperluan output.

\section{Data Flow Diagram Level 2}

Data Flow Diagram Level 2 lebih diuraikan lagi dari Data Flow Diagram Level 1, pada Gambar 5 diuraikan diagram login.

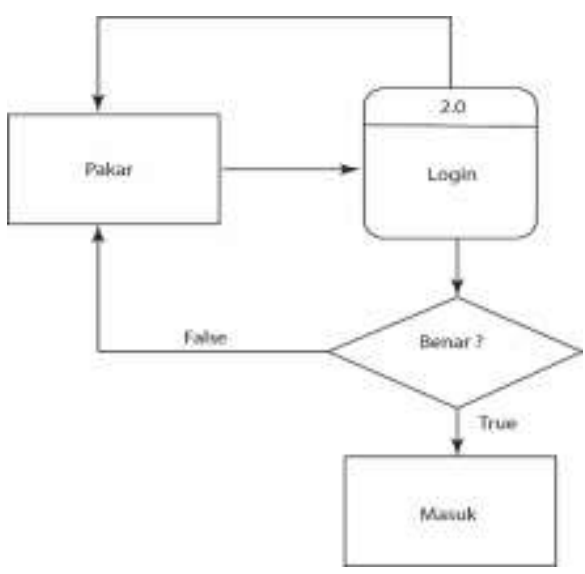

Gambar 5 Data Flow Diagram Level 2

Pada Gambar 5, seorang pakar harus login terlebih dahulu, jika email dan password yang dimasukan benar maka pakar bisa mengakses form pakar dan mengakses kedalam database, lalu database akan menampilkan output (hasil) yang terdapat didalam database ke form pakar, jika email dan password yang dimasukan salah maka akan ada pemberitahuan error yang terjadi dan akan diminta memasukan kembali email dan password.

\section{HASIL PENELITIAN}

Hasil dari penelitian ini akan memberikan rancangan data base dari sistem pakar, mengenai penerapan aplikasi dari hasil analisis dan perancangan sistem yang telah dipaparkan, serta perangkat yang dibutuhkan untuk menjalankan aplikasi ini.

1. Perancangan database yang terdiri dari beberapa tabel yaitu :

a. Tabel Penyakit

Tabel ini berfungsi untuk menyimpan informasi mengenai jenis penyakit hipertensi yang ada serta saran yang diberikan sesuai dengan jenis penyakitnya

Tabel 1. Penyakit

\begin{tabular}{|c|c|c|}
\hline Nama Data & Tipe Data & Length/Values \\
\hline Kode & varchar & 20 \\
\hline penyakit & varchar & 50 \\
\hline Saran & varchar & 5000 \\
\hline
\end{tabular}

b. Tabel Gejala

Tabel ini berfungsi untuk menyimpan seluruh data gejala yang dialami penderita penyekit hipertensi

Tabel 2.Gejala_penyakit

\begin{tabular}{|c|c|c|}
\hline Nama Data & Tipe Data & Length/Values \\
\hline no & int & 11 \\
\hline kode & varchar & 10 \\
\hline nama_gejala & varchar & 50 \\
\hline
\end{tabular}

c. Tabel Rule

Tabel ini berfungsi untuk menyimpan aturan yang mencocokan gejala dengan jenis penyakitnya.

Tabel 3. Rule

\begin{tabular}{|c|c|c|}
\hline Nama Data & Tipe Data & Length/Values \\
\hline kode_penyakit & varchar & 20 \\
\hline Kode_gejala & varchar & 20 \\
\hline
\end{tabular}

d. Tabel dokter

Tabel ini berfungsi untuk merekam data dokter sehingga dokter dapat mengakses sistem pakar dalam mengolah data kepakaran sistem.

Tabel 4. Dokter

\begin{tabular}{|c|c|c|}
\hline Nama Data & Tipe Data & Length/Values \\
\hline username & varchar & 50 \\
\hline nama_depan & varchar & 50 \\
\hline nama_belakang & varchar & 50 \\
\hline email & varchar & 100 \\
\hline pass & varchar & 50 \\
\hline salt & varchar & 50 \\
\hline
\end{tabular}

e. Tabel relasi penyakit dengan gejala

Tabel ini berisi informasi dari gejala-gejala yang diderita dari setiap jenis penyakit dari hipertensi. 
Tabel 5. Relasi Gejala Dan Penyakit

\begin{tabular}{|c|c|c|c|c|c|c|}
\hline $\begin{array}{c}\text { Kode } \\
\text { _geja } \\
\text { la }\end{array}$ & Nama_gejala & $\mathrm{P} 1$ & $\mathrm{P} 2$ & $\mathrm{P} 3$ & $\mathrm{P} 4$ & P5 \\
\hline G1 & Sakit Kepala & $\mathrm{T}$ & $\mathrm{T}$ & & & \\
\hline G2 & Pusing & $\mathrm{T}$ & & & & \\
\hline G3 & Penglihatan Buram & $\mathrm{T}$ & & & & \\
\hline G4 & Mual & $\mathrm{T}$ & $\mathrm{T}$ & & & \\
\hline G5 & $\begin{array}{c}\text { Telinga } \\
\text { Berdenging }\end{array}$ & $\mathrm{T}$ & & & & \\
\hline G6 & Kebingungan & $\mathrm{T}$ & & & & \\
\hline G7 & $\begin{array}{l}\text { Detak Jantung } \\
\text { Tidak Teratur }\end{array}$ & $\mathrm{T}$ & & & & \\
\hline G8 & Sering Keleleahan & $\mathrm{T}$ & & & & \\
\hline G9 & $\begin{array}{c}\text { Rasa Nyeri Di } \\
\text { Dada }\end{array}$ & $\mathrm{T}$ & & & & \\
\hline G10 & Kesulitan Bernafas & $\mathrm{T}$ & & & & \\
\hline G11 & Darah Dalam Urine & $\mathrm{T}$ & & & & \\
\hline G12 & $\begin{array}{c}\text { Sensasi Berdetak } \\
\text { Di Dada, } \\
\text { Leher, atau Telinga }\end{array}$ & $\mathrm{T}$ & & & & \\
\hline G13 & $\begin{array}{c}\text { Keringat } \\
\text { Berlebihan }\end{array}$ & & $\mathrm{T}$ & & & \\
\hline G14 & Jantung Berdebar & & $\mathrm{T}$ & & & \\
\hline G15 & Cemas & & $\mathrm{T}$ & & & \\
\hline G16 & Kejang & & $\mathrm{T}$ & & & \\
\hline G17 & Sesak Nafas & & $\mathrm{T}$ & & & \\
\hline G18 & $\begin{array}{c}\text { Terbangun dari } \\
\text { tidur akibat merasa } \\
\text { tercekik }\end{array}$ & & & & & $\mathrm{T}$ \\
\hline G19 & Muntah & & $\mathrm{T}$ & & & \\
\hline G20 & Lemas & & $\mathrm{T}$ & $\mathrm{T}$ & $\mathrm{T}$ & \\
\hline G21 & $\begin{array}{c}\text { Pertumbuhan } \\
\text { rambut Abnormal }\end{array}$ & & & $\mathrm{T}$ & & \\
\hline G22 & $\begin{array}{l}\text { Muncul Garis } \\
\text { Ungu Dutubuh }\end{array}$ & & & $\mathrm{T}$ & & \\
\hline G23 & $\begin{array}{l}\text { Benjolan Di leher } \\
\text { Belakang }\end{array}$ & & & $\mathrm{T}$ & & \\
\hline G24 & Kram Otot & & & & $\mathrm{T}$ & \\
\hline $\mathrm{G} 25$ & Kesemutan & & & & $\mathrm{T}$ & \\
\hline G26 & $\begin{array}{c}\text { Nafsu Makan } \\
\text { Menghilang }\end{array}$ & & & & $\mathrm{T}$ & \\
\hline G27 & $\begin{array}{l}\text { Mengantuk Di } \\
\text { siang Hari }\end{array}$ & & & & & $\mathrm{T}$ \\
\hline G28 & $\begin{array}{l}\text { Nafas Berhenti } \\
\text { Saat Tidur }\end{array}$ & & & & & $\mathrm{T}$ \\
\hline
\end{tabular}

2. Hasil Implementasi sistem pakar di Lingkungan User adalah sebagai berikut:

a. Menu Utama

Di menu utama user bisa masuk ke dalam penjelasan untuk mengetahui semua tentang hipertensi dan pakar bisa masuk kedalam halaman login melalui halaman ini.

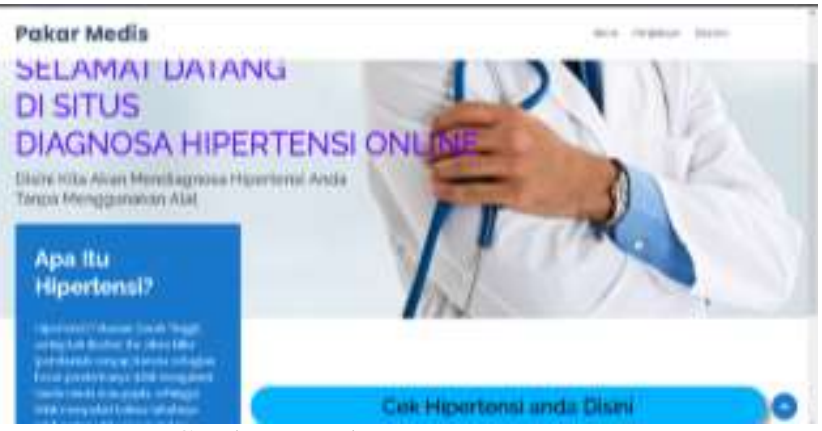

Gambar 6 Halaman Utama

b. Daftar Pertanyaan

Dihalaman ini user bisa memilih gejala yang diderita untuk mengetahui hasil diagnosa dari gejala yang ditemukan

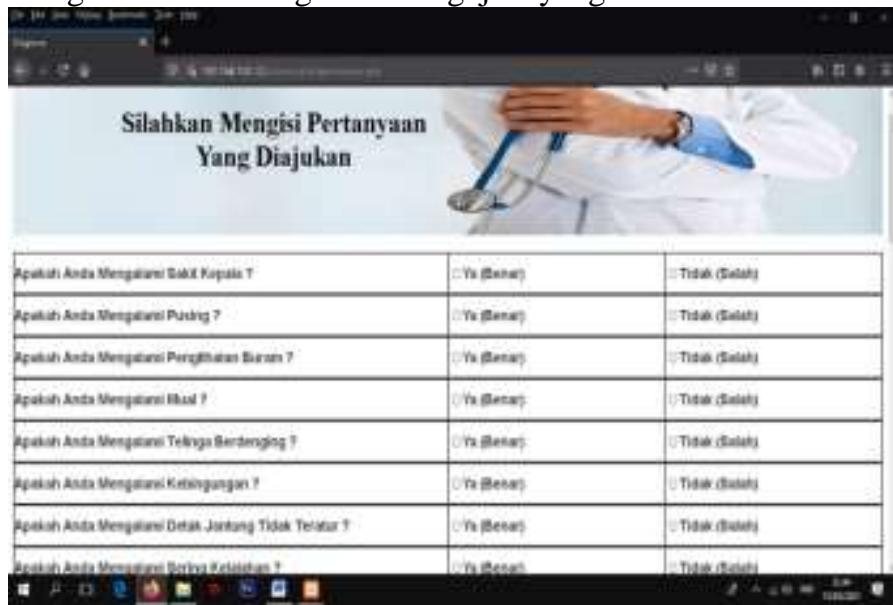

Gambar 7 Halaman Pertanyaan 1

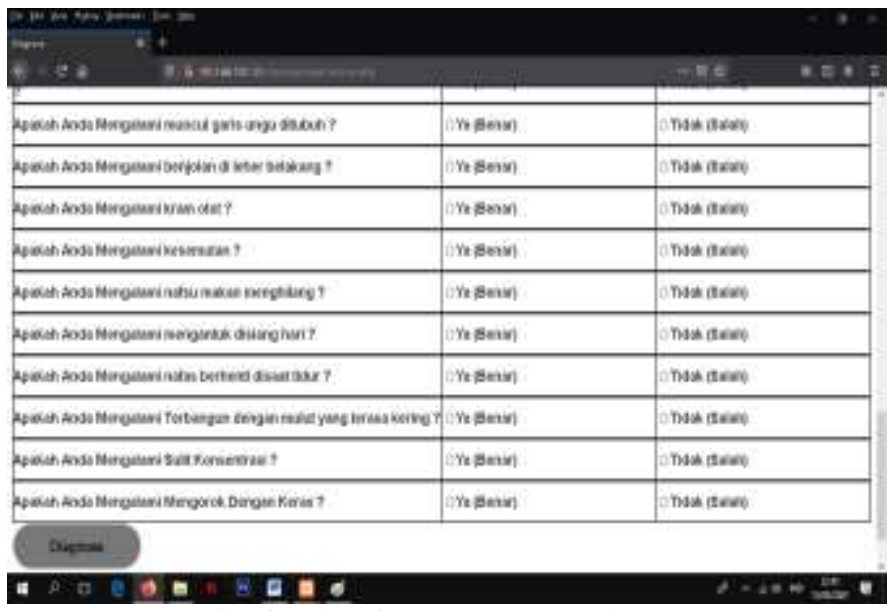

Gambar 8 Halaman Pertanyaan 2

c. Hasil Diagnosa dan Saran

Halaman ini akan menampilkan hasil diagnosa user,didalam halaman ini user dapat melihat kemungkinan penyakit hipertensi apa yang dialami oleh user dan tingkat kepastian dari masing-masing penyakit yang ada didaftar dan saran dari penyakit yang diderita. 


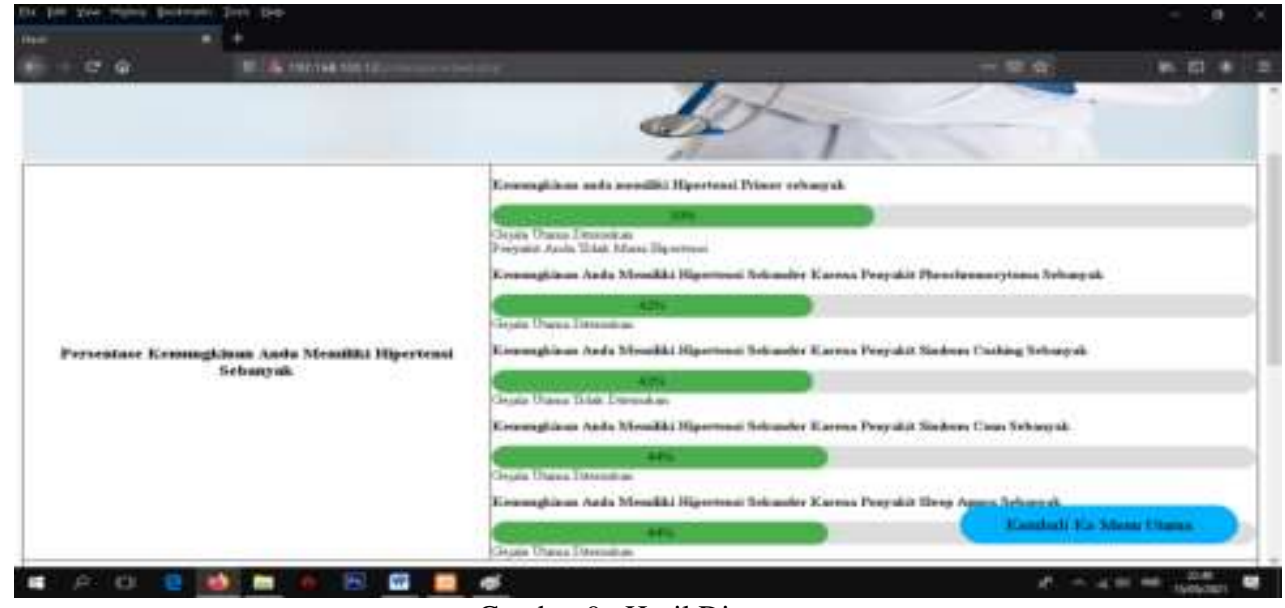

Gambar 9. Hasil Diagnosa

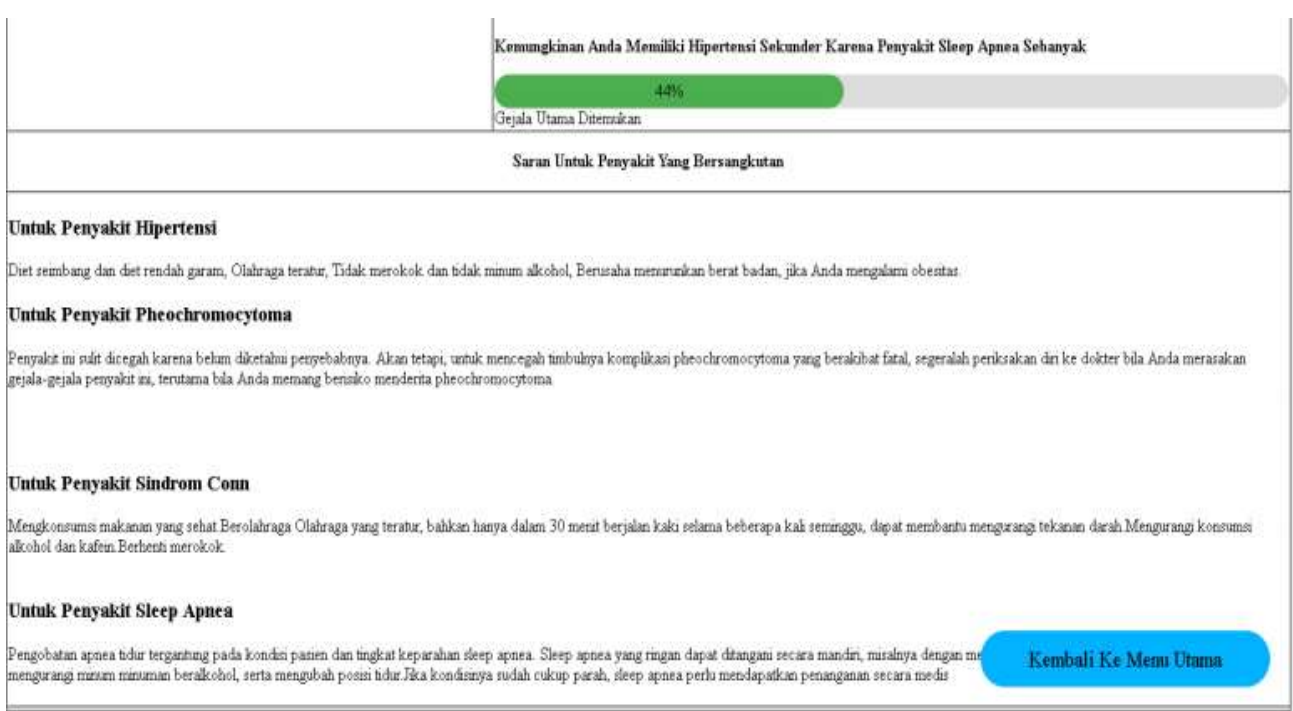

Gambar 10. Saran

\section{Login Pakar}

Dihalaman ini pakar bisa memasukan email dan password untuk masuk ke halaman pakar

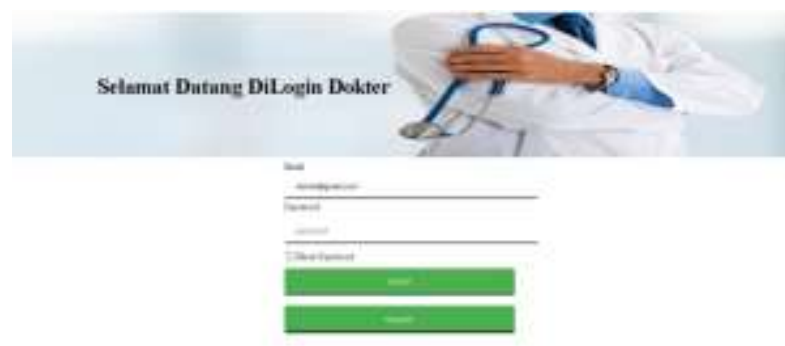

Gambar 11. Login Pakar

5.Register Pakar

Form ini digunakan untuk melakukan registrasi pakar baru

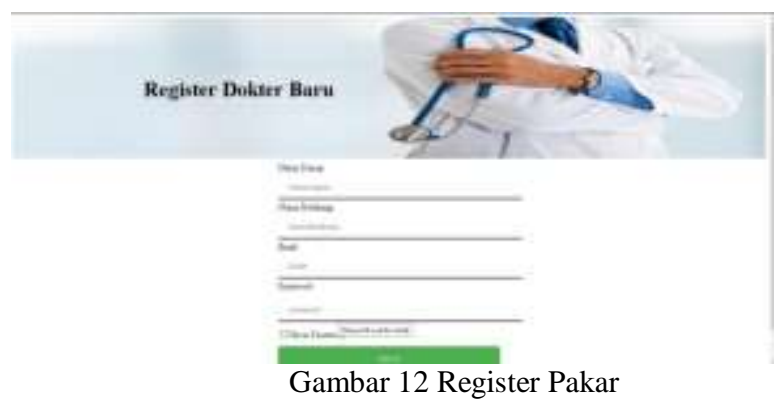

\section{KESIMPULAN}

Setelah melalui tahap analisis, perancangan, implementasi dan pengujian aplikasi sistem pakar diagnosa penyakit hipertensi dengan menggunakan Metode Forward Chaining, maka dapat ditarik kesimpulan bahwa sistem pakar diagnosa penyakit hipertensi ini telah berhasil dibangun sehingga bisa menjadi suatu media informasi, pengetahuan dan sarana deteksi (berdasarkan gejala atau keluhan) bagi orang awan dalam mendeteksi kondisi awal dari penyakit hipertensi secara mandiri dengan bantuan teknologi, dan dengan aplikasi ini diharapkan dapat membantu dalam memberikan konsultasi bagi mayarakat Indonesia untuk mendapatkan informasi dan penanganan tentang hipertensi. Saran berdasarkan aplikasi yang 
dirancang oleh penulis adalah aplikasi dikembangkan dengan meningkatkan kepastian untuk hipertensi sekunder dan aplikasi dapat dikembangkan dalam user interface yang dapat mensupport pada semua platform seperti Android, Mac, Tablet dan lain-lain.

\section{DAFTAR PUSTAKA}

[1]. "Waspada! 5 Jenis Penyakit Penyebab Kematian Tertinggi di Indonesia", siloamhospitals, 2 January 2020, [Online]. Tersedia: https://www.siloamhospitals.com/Contents/NewsEvents/Advertorial/2020/01/27/12/22/5-JenisPenyakit-Penyebab-Kematian-Tertinggi

[2]. Ferri, Ferri's Clinical Advisor ,Books in 1, Philadelphia:Elsevier, 2017.

[3]. "Sistem Pakar," 19 September 2020. [Online]. Tersedia:

https://id.wikipedia.org/wiki/Sistem_pakar

[Diakses: 7 Desember 2020]. Licensed By Lisensi Creative Commons Atribusi-Berbagi Serupa 3.0.

[4]. Irwan, Epidemiologi Penyakit Tidak Menular. Yogyakarta: Deepublish., 2016

[5]. Ignatavicius, Workman, \& Rebar, Medical Surgical Nursing: Concepts For Interprofessional Collaborative Care (9thed.), St. Louis : Elsevier ,2017

[6]. Ihda Fadila, Hipertensi (Tekanan Darah Tinggi), 28 Januari 2021[Online]. Tersedia https://hellosehat.com/jantung/hipertensi/pengertian -hipertensi/, Ditinjau Oleh dr. Tania Savitri - Dokter Umum [diakses: 5 Maret 2021] 